\title{
Survival Outcomes According to TIMP1 and EGFR Expression in Heavily Treated Patients with Advanced Non-small Cell Lung Cancer who Received Biweekly Irinotecan Plus Bevacizumab
}

\author{
BEATRIZ WILLS ${ }^{1,2^{*}}$, ANDRÉS F. CARDONA ${ }^{1,3,4^{*}}$, LEONARDO ROJAS $^{5,6^{*}}$, ALEJANDRO RUIZ-PATIÑO $^{6 *}$, \\ OSCAR ARRIETA $^{7 *}$, NOEMÍ REGUART ${ }^{8}$, HERNÁN CARRANZA ${ }^{1,3,4}$, CARLOS VARGAS $^{1,3,4}$, \\ JORGE OTERO ${ }^{1,3,4}$, LUIS CORRALES $^{9}$, CLAUDIO MARTÍN ${ }^{10}$, MAURICIO CUELLO ${ }^{11}$, \\ LUIS EDUARDO PINO ${ }^{12}$, CHRISTIAN ROLFO ${ }^{13}$, RAFAEL ROSELL ${ }^{14}$ and ZYANYA LUCIA ZATARAIN-BARRÓN ${ }^{7}$; \\ on behalf of The Latin-American Consortium for the Investigation of Lung Cancer (CLICaP) \\ ${ }^{1}$ Foundation for Clinical and Applied Cancer Research (FICMAC), Bogota, Colombia; \\ ${ }^{2}$ Internal Medicine Department, Johns Hopkins University, Baltimore, MD, U.S.A.; \\ ${ }^{3}$ Clinical and Translational Oncology Group, Institute of Oncology, Clínica del Country, Bogota, Colombia; \\ ${ }^{4}$ Research Department, University of Bosque, Bogota, Colombia; \\ ${ }^{5}$ Oncology Department, Javeriana Oncology Center, San Ignacio Hospital, Bogota, Colombia; \\ ${ }^{6}$ Faculty of Medicine, Javeriana University, Bogotá, Colombia; \\ ${ }^{7}$ Thoracic Oncology Unit, Instituto Nacional de Cancerología (INCan), Mexico City, Mexico; \\ ${ }^{8}$ Medical Oncology Department, Hospital Clínic, Barcelona, Spain; \\ ${ }^{9}$ Clinical Oncology Department, Hospital San Juan de Dios, San Jose, Costa Rica; \\ ${ }^{10}$ Thoracic Oncology Unit, Alexander Fleming Institute, Buenos Aires, Argentina; \\ ${ }^{11}$ Clinical Oncology Department, Clinics Hospital, University of the Republic (UdeLAR), Montevideo, Uruguay; \\ ${ }^{12}$ Medical Oncology Group, Santa Fe Foundation, Bogota, Colombia; \\ ${ }^{13}$ Early Clinical Trials Unit, Oncology Department, Antwerp University Hospital and \\ Center for Oncological Research (CORE), Antwerp University, Edegem, Belgium; \\ ${ }^{14}$ Medical Oncology Department, Catalan Institute of Oncology, University \\ Hospital "Germans Trias i Pujol", Barcelona, Spain
}

\begin{abstract}
Background: Heavily treated patients with nonsmall cell lung cancer (NSCLC) have few treatment options, while irinotecan and bevacizumab have proven synergistic action in preclinical studies. Patients and Methods: A total of 49 patients with heavily treated NSCLC were enrolled from
\end{abstract}

This article is freely accessible online.

*These Authors contributed equally to this study.

Correspondence to: Andrés Felipe Cardona, MD, M.Sc., Ph.D., Foundation for Clinical and Applied Cancer Research - FICMAC Calle 116 No. 9-72, c. 318, Bogotá, Colombia. Tel: +57 16190052 , Fax: +57 16190053, e-mail: andres.cardona@clinicadelcountry.com; a_cardonaz@yahoo.com

Key Words: Irinotecan, bevacizumab, TIMP1, EGFR mutation, gene expression.
2011-2014 and treated with irinotecan and bevacizumab. Treatment response along with mutational status of epidermal growth factor receptor (EGFR), and tissue inhibitor of metalloproteinases-1 (TIMP1) and EGFR expression were evaluated. Progression-free (PFS) and overall (OS) survival were monitored. Results: Median follow-up was 13.2 months. Twenty-three patients had received three or more prior therapy lines. Overall response rate was $32 \% \quad[95 \%$ confidence interval $(C I)=22 \%-39 \%$ ] and $26 \%$ of patients achieved stable disease. Median PFS was 4.4 (95\% CI=2.88.3) months and median OS 18.0 (95\% CI=16.2-30.7) months. Nine patients harboring EGFR mutations had a longlasting partial response. A shorter OS was found in patients with a higher TIMP1 expression $(p=0.006)$. Conclusion: Irinotecan combined with bevacizumab had favorable antitumor activity in heavily pretreated patients with NSCLC. These results suggest this is a reasonable strategy, particularly for patients with low TIMP1 expression. 
Non-small cell lung cancer (NSCLC) is one of the most common malignancies worldwide, accounting for approximately $80-85 \%$ of all lung cancer cases. Patients with advanced or metastatic NSCLC often benefit from platinumcontaining regimens and targeted therapies. Nevertheless, only $16 \%$ of patients with advanced disease who lack activating mutations survive more than 2 years (1). Research suggests that long-term survivors are likely to present with few metastases, absence of bone lesions, favorable performance status (PS) (0-1) at first progression and treatment response to either: first- or second-line chemotherapy or maintenance therapy. Additionally, time to first disease progression of more than 3 months and further treatment strategies are significant predictors for long-term survival $(2,3)$.

Due to their favorable safety profile and survival benefit in a subset of patients, novel biological and targeted therapies have been increasingly used. Despite these new treatment strategies, the role of third-line or higher chemotherapy for patients with NSCLC is still controversial (3). It is, therefore, important to understand if prolonged survival is the result of the introduction of novel therapies or, instead, a consequence of population heterogeneity, corresponding to a multimodal survival distribution (4).

One treatment strategy that has been studied for advanced NSCLC is irinotecan (CPT-11), a water-soluble pro-drug that is metabolized in vivo to SN-38, with 100 to 1,000 -fold greater cytotoxicity compared to the parent compound. Cytotoxic effects of SN-38 are mediated through its interaction with topoisomerase I (TOPO1), an enzyme that relieves torsional strain during DNA replication and transcription (5). Specifically, during cell division, DNA replication forks collide with enzyme-DNA cleavage complexes, resulting in double-stranded DNA breaks and subsequent programmed cell death (6).

Previous first-linephase III trials failed to demonstrate statistically significant differences in response rate (RR), overall survival (OS), progression-free survival (PFS), or time to treatment failure (TTF) with cisplatin-irinotecan doublet therapy and other standard first-line regimens with platinum compound plus paclitaxel, docetaxel, gemcitabine, or vinorelbine (7). However, therapeutic synergy between irinotecan and bevacizumab has been demonstrated in both human lung cancer xenograft models and several colon cancer clinical trials (8-10). An additional advantage of irinotecancontaining regimens lies in its acceptable toxicity profile in patients with NSCLC. In a previous report, only the physical domain evaluated by the Quality of Life Questionnaire for Cancer Patients Treated with Anti-Cancer Drugs was hampered due to unpredictable diarrhea (7). Interestingly, some researchers have documented that patients harboring epidermal growth factor receptor $(E G F R)$ mutations have abnormal TOPO1 activity due to increased TOPO1 mRNA and protein expression from tyrosine-protein kinase Met (MET) signaling. Therefore, it has been hypothesized that these patients could benefit from irinotecan (11).

In the past decade, several tumor markers have been used in the evaluation of solid malignancies. For example, tissue inhibitor of metalloproteinases-1 (TIMP1) belongs to a family of glycoproteins that are natural inhibitors of matrix metalloproteinases (MMPs). Such enzymes are involved in extracellular matrix maintenance and remodeling (12). The TIMP family consists of four members (TIMP1-4). Specifically, TIMP1 differs in the short exon 1, which is transcribed but not translated. Research has suggested that exon 1 contains tissue-specific repressor elements and may be involved in tissue expression specificity $(12,13)$. Additionally, TIMP-independent MMP activities include promotion of cell growth and anti-apoptotic activity (13). Such effects are likely mediated by their direct binding to cell-surface receptors and subsequent signaling activation, including the mitogen-activated protein kinase and the cyclic adenosine 3',5'-monophosphate-protein kinase A (PKA) pathways $(14,15)$. TIMP1 has been extensively studied in recent years as a promising prognostic marker in colorectal, endometrial and breast cancer (16-22). Recently, Spindler et al. showed that TIMP1 has a potential role as a prognostic biomarker in patients with metastatic colorectal cancer treated with cetuximab and irinotecan. The authors documented that higher TIMP1 levels were associated with shorter PFS and significantly lower OS (23). Similarly, an increasing level of TIMP1 has been correlated with chemotherapy resistance in metastatic breast cancer, likely explained by anti-apoptotic activity induced by TIMP1. Conversely, the significance of TIMP1 in terms of survival outcomes in patients with NSCLC is still contradictory.

Furthermore, platinum-based chemotherapy in combination with third-generation or newer antitumor agents, such as irinotecan, improves survival and quality of life of patients with advanced NSCLC $(7,24,25)$. The addition of bevacizumab achieves a longer PFS (26). In the subpopulation of patients harboring EGFR mutations, a dramatic benefit from tyrosine kinase inhibitors such as erlotinib and gefitinib has been observed (27-29). Despite the introduction of these new treatment agents, disease in most patients will eventually progress. These patients, however, will maintain a good performance status (PS), making them suitable candidates for further chemotherapy (30). On the other hand, the efficacy of third-line and later chemotherapy regimens in terms of tumor response, survival benefit and toxicity has not been established. The objective of the present study was to evaluate survival outcomes and toxicity profile in heavily treated patients ( $>3$ lines) with metastatic NSCLC who received irinotecan plus bevacizumab, and to further determine the association of TIMP1 and EGFR expression with prognosis. 


\section{Patients and Methods}

A prospective evaluation of 49 patients with metastatic heavily treated NSCLC who received biweekly irinotecan plus bevacizumab was conducted. Tumor responses were evaluated by the Response Evaluation Criteria of Solid Tumors (RECIST 1.1) (31). Toxicity was assessed according to the Common Terminology Criteria for Adverse Events version 4.0 (32).

Patient selection. Adult patients ( $>18$ years of age) were eligible after histological confirmation of stage IV NSCLC. Inclusion criteria for enrollment were: i) quantifiable anatomic disease (at least one area which had not been subject to prior radiation); ii) prior chemotherapy (including one line with a platinum containing regimen with or without bevacizumab, a taxane and a tyrosine kinase inhibitor); iii) at least 2 weeks since last chemotherapy or radiation therapy, and full recovery from any adverse effects; iv) Eastern Cooperative Oncology Group (ECOG) PS of 0 , 1, or 2; v) no active invasive second malignancy; vi) adequate organ function defined by: PS: 0-1; life expectancy of at least 12 weeks; hematopoietic system: absolute neutrophil count at least $1,500 / \mathrm{mm}^{3}$, platelet count at least $100,000 / \mathrm{mm}^{3}$; hepatic: total bilirubin, aspartate transaminase, and alanine transaminase (ALT) of less than two times the upper limit of normal (UNL); renal: creatinine $<2.5$ times ULN; cardiovascular: New York Heart Association class I or II.

Patients were excluded if there was: i) active or uncontrolled infection, bleeding or tissue scar; ii) significant cardiovascular disease (uncontrolled hypertension, unstable angina, acute congestive heart failure, myocardial infarction within the previous 6 months, or uncontrolled serious arrhythmia); iii) pregnancy, lactation, or refusal to use effective contraception; iv) Gilbert's disease considering evidence of excessive irinotecan-induced neutropenia; v) uncontrolled diabetes mellitus; or vi) any other severe, concurrent illness which in the judgment of the investigator would make the patient inappropriate to enter this study. All study candidates were required to provide written informed consent as approved by the Institutional Review Board.

Treatment plan. A 90-min intravenous infusion of $125 \mathrm{mg} / \mathrm{m}^{2}$ irinotecan was given on days 1 and 8 plus $7.5 \mathrm{mg} / \mathrm{kg}$ bevacizumab on day 1 , repeated every 3 weeks. Treatment was administered until unacceptable drug toxicity or disease progression.

Evaluation plan. Before receiving treatment, patients underwent a thorough evaluation including medical history (and concomitant medications), physical examination and determination of their PS.

Additionally, complete blood count (CBC) and serum creatinine prior to each treatment were obtained. After treatment initiation, physical examination, PS, weight, and full serum chemistries were repeated prior to each 3-week cycle (including CBC and liver function tests). Computed tomographic/magnetic resonance images were obtained every two cycles and all toxicities were graded according to the Common Terminology Criteria for Adverse Events version 4.0 (32). Irinotecan doses were adjusted according to the degree of toxicity. Specifically, the irinotecan dose was reduced by $10 \mathrm{mg} / \mathrm{m}^{2}$ for grade 2-3 hematological toxicities and by $20 \mathrm{mg} / \mathrm{m}^{2}$ for diarrhea. Treatment was discontinued for grade 4 diarrhea, neutropenic fever, grade 3 or greater hemorrhage, grade 4 non-hematological toxicity, arterial thrombosis, gastrointestinal perforation and wound dehiscence requiring medical or surgical intervention.
Tumor samples. Diagnostic tissue consisted of formalin-fixed paraffin-embedded tissue from a gross-needle biopsy or surgical specimen. All samples were re-evaluated by the same pathologist who made the initial diagnosis to confirm the diagnosis. Samples were classified using the 2011 IASLC/ATS/ERS classification (33). Tumor blocks were evaluated based on tumor cell percentage. Tumor cell content was below $30 \%$ in most samples (72\%) and below $10 \%$ in the remaining blocks. Most biopsies $(n=32)$ were from the primary tumor. When unable to perform the molecular analysis on the primary tumor, mutation detection, protein expression and mRNA expression were performed on lymph nodes in five cases and distant metastasis in 12 .

DNA extraction from paraffin-embedded tissue. Five slices were cut from the paraffin-embedded blocks. The two outermost sections were stained with hematoxylin/eosin. When tumor cells were identified in both sections, the three middle slices were used for DNA extraction. Sections were deparaffinized by submersion in xylene and rehydrated with ethanol. DNA was extracted using the QIAamp DNA FFPE Tissue Kit (Qiagen, Germany) according to the manufacturer's protocol.

EGFR mutation and protein expression status. The Cobas ${ }^{\circledR}$ EGFR and K-RAS Tissue Test (Roche ${ }^{\circledR}$ Pleasanton, CA, USA) was used for mutation detection. The test is designed to detect G719A/C/S in exon 18; 29 deletions in exon 19; S768I, T790M and five insertions in exon 20; and L858R in exon 21. The Cobas ${ }^{\circledR} 4800$ SR2 System Software v2.0 and EGFR Analysis Package Software v1.0 were used for analysis (Roche Diagnostics, Indianapolis, IN, USA). EGFR protein expression was measured using the EGFR pharmDx kit and autostainer (DAKO, Carpinteria, CA, USA) according to the manufacturer's instructions (34). Samples were categorized as EGFR protein-expression IHC-positive if there was evidence of membranous staining in $>1 \%$ of tumor cells.

Quantitative estimation of TIMP1 mRNA expression. Using reversetranscription real-time PCR, total RNA was isolated from $100 \mathrm{mg}$ of 88 pairs of tumor and control lung tissue using the FastRNAPro Green Kit (QBIO gene, Irvine, CA, USA). Reverse transcription was performed on $3 \mu \mathrm{g}$ of total RNA with Superscript III Reverse Transcriptase (Life Technologies, Carlsbad, CA, USA) and oligo $\mathrm{d}(\mathrm{T}) 21$ as a primer. The sequence of primers used for TIMP1 mRNA quantification was as follows: forward primer: 5'-AGACC TACACTGTTGGCTGTGAG-3'; reverse primer: 5'-GACTGGAAG CCCTTTTCAGAG-3', synthesized by GeneriBiotech (Roche Diagnostics, Bogotá, Colombia). All samples were assessed for the expression of the gene glyceraldehyde-3-phosphate dehydrogenase $(G A P D H)$. TIMP1 mRNA expression was continuously quantified. The real-time PCR procedure and the sequence of GAPDH primers were previously described by Pesta et al. (35)

Statistical analysis. The primary study endpoint was PFS, defined as the interval between the date treatment started and the date of documented disease progression or death from any cause. OS was defined as the interval between the date treatment started and the date of death from any cause. Patients lost to follow-up were censored at the last date of contact. Secondary endpoints included overall response rate (ORR), defined as the proportion of patients whose best response was complete response (CR) or partial response (PR), and toxicity. A two-staged Simon accrual design was used. An 
Table I. Patient characteristics.

\begin{tabular}{lcc}
\hline Variable & $\mathrm{N}(\%)$ & $95 \% \mathrm{CI}$ \\
\hline Female gender & $22(43 \%)$ & $29-57 \%$ \\
Median age & $60(44-78)$ & $57-62.5 \%$ \\
Frequency of metastatic disease & $47(92 \%)$ & $84-96 \%$ \\
Histological pattern & & \\
$\quad$ Acinar & $27 \%$ & \\
Lepidic & $14 \%$ & \\
Papillary/micropappilary & $22 \%$ & \\
Solid & $21 \%$ & \\
Non-specified & $16 \%$ & \\
Frequency of smokers & $23(53 \%)$ & $39-67 \%$ \\
Metastasis site & & \\
Lung & $80 \%$ & \\
Bone & $45 \%$ \\
CNS & $49 \%$ \\
Liver & $74 \%$ \\
Frequency of symptoms & & \\
Dyspnea & $35 \%$ \\
Cough & $47 \%$ \\
Pain & $14 \%$ \\
Weight loss & $37 \%$ \\
\hline
\end{tabular}

CI: Confidence interval; CNS: central nervous system.

Table II. Molecular and clinical profiles $(N=49)$.

\begin{tabular}{lcc}
\hline Variable & $\mathrm{N}(\%)$ & $95 \% \mathrm{CI}$ \\
\hline $\begin{array}{l}\text { Frequency of EGFR mutation } \\
\text { Exon }\end{array}$ & $14(29 \%)$ & $16-42 \%$ \\
$\quad 18$ & $1(7 \%)$ & \\
19 & $9(64 \%)$ & \\
$21 \mathrm{~L} 858 \mathrm{R}$ & $4(29 \%)$ & \\
EGFR overexpression & $13(27 \%)$ & $15-39 \%$ \\
TIMP mRNA expression & $24(49 \%)$ & $35-63 \%$ \\
Molecular profile among smokers & & \\
EGFR mutation & $2(8.7 \%)$ & $1-17 \%$ \\
$\quad$ EGFR expression & $10(43 \%)$ & $29-57 \%$ \\
TIMP mRNA expression & $15(65 \%)$ & $52-79 \%$ \\
\hline
\end{tabular}

EGFR: Epidermal growth factor receptor; TIMP1: tissue inhibitor of metalloproteinases-1; CI: confidence interval.

ORR of $15 \%$ was assumed for different therapies in heavily pretreated ( $>3$ lines) patients with NSCLC, and a target response rate of $25 \%$ was established. Assuming a dropout rate of $10 \%$, a sample size of 42 patients provided at least $80 \%$ power and type 1 error of $<5 \%$. For statistical purposes, continuous variables are summarized as arithmetic means, medians and standard deviations. Categorical variables are reported as proportions with $95 \%$ confidence intervals (95\% CI). Inferential comparisons were performed using Student's $t$-test, chi-squared and Fisher's exact tests to assess significance of categorical variables. The time-to-event variables obtained from the Kaplan-Meier method were determined by log-rank tests. To test
Table III. Treatment response $(N=49)$.

\begin{tabular}{lcc}
\hline & $\mathrm{N}(\%)$ & $95 \% \mathrm{CI}$ \\
\hline Global response & & \\
$\quad$ Tyrosine kinase inhibitors & $18(37 \%)$ & $23-51 \%$ \\
$\quad$ Irinotecan/bevacizumab & $16(33 \%)$ & $20-46 \%$ \\
Irinotecan/bevacizumab response & & \\
$\quad$ Complete & $1(2 \%)$ & \\
Partial & $15(33 \%)$ & \\
Stable disease & $20(41 \%)$ & \\
Disease progression & $13(24 \%)$ \\
\hline
\end{tabular}

CI: Confidence interval.

association of TIMP1 mRNA expression with clinical, and pathological features, Kruskal-Wallis and Mann-Whitney $U$-tests were used. Statistical significance was determined as $p \leq 0.05$ with a two-sided test. All statistical analysis was performed with SPSS version 19.0 (IBM Corp., Armonk, NY, USA).

\section{Results}

Patient characteristics. A total of 49 patients were enrolled from one institution in Bogotá (Colombia) between March 2011 and November 2014. Demographic and clinical baseline characteristics are summarized in Table I. The median age was 60 years (range $=44-78$ years), $57 \%$ were male and $75 \%$ had an ECOG PS of $0-1$. Most patients had received on average three previous lines of therapy, and 16 patients had previously received bevacizumab as a first line, while 11 (22.4\%) had received radiotherapy. The most common histological pattern was acinar followed by papillar and solid. Nearly half of the patients were non-smokers. The entire patient population had previously received one or two platinum-based chemotherapy regimens and 23 patients had previously received more than three lines. Distant metastasis and symptoms such as dyspnea and weight loss are summarized in Table I.

Molecular profile and clinical characteristics. The molecular profile and clinical characteristics are summarized in Table II. Fourteen patients (28\%) harbored EGFR mutations; specifically, 50\% had exon 19 deletion. Sixteen patients (32\%) had EGFR overexpression and $49 \%$ had high levels of TIMPl mRNA, while only one patient had a positive KRAS mutation. EGFR overexpression was not increased among smokers $(p=0.11)$, however, it was significantly higher in patients without EGFR mutations $(p=0.015)$. Additionally, TIMP1 expression was higher in current/former smokers $(p=0.031)$, among those without EGFR mutation $(p=0.040)$ and in those whose disease progressed during treatment with irinotecan-bevacizumab $(p=0.050)$. 

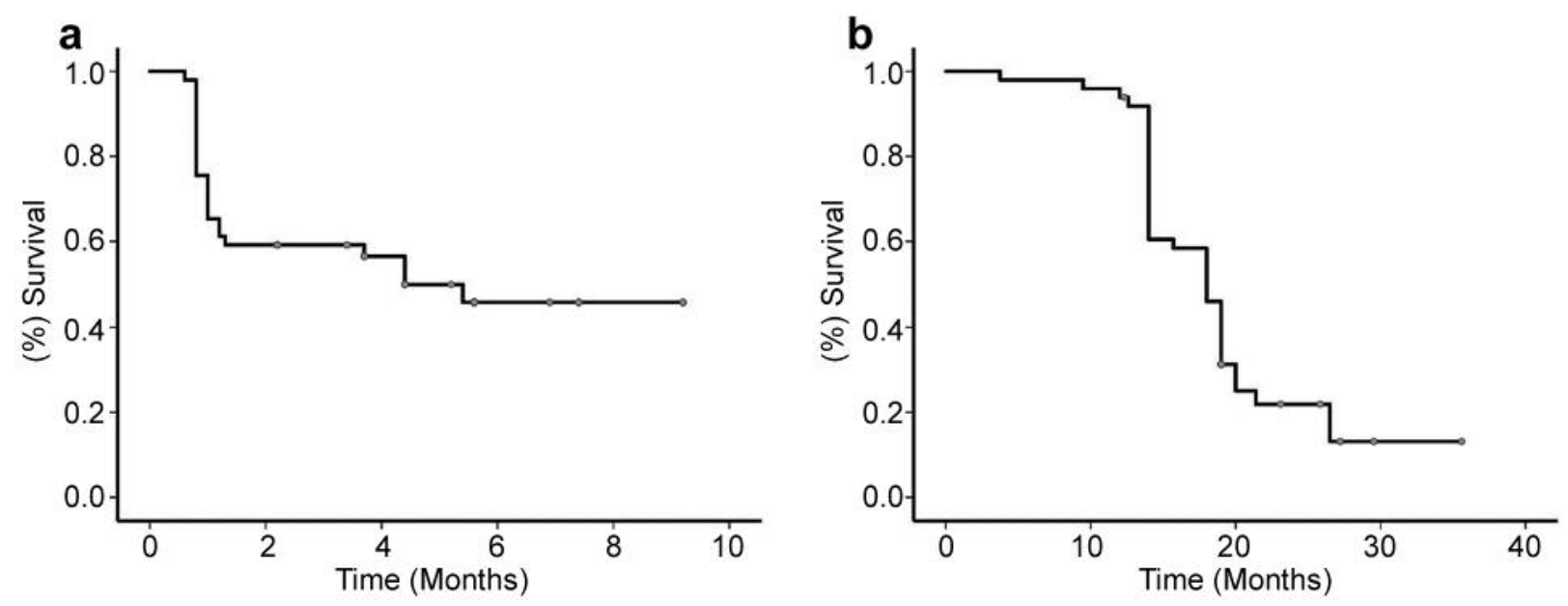

Figure 1. Progression-free $(A)$ and overall $(B)$ survival among patients treated with irinotecan plus bevacizumab.
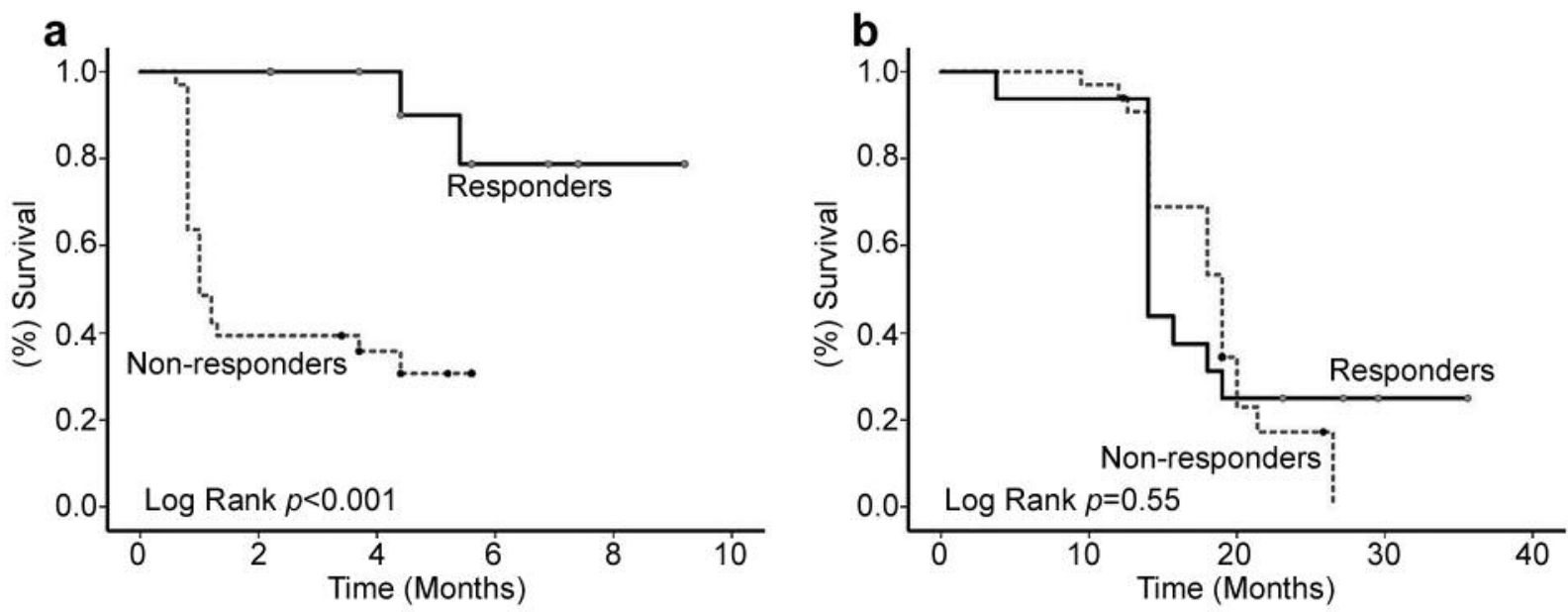

Figure 2. Progression-free (A) and overall (B) survival among patients treated with irinotecan plus bevacizumab according to response.

Treatment response and survival. Treatment response and survival are presented in Table III. Median follow-up was 13.2 months. Twenty-nine out of the 49 total patients (59\%) experienced clinical benefit with an ORR of $32 \%(95 \%$ $\mathrm{CI}=22 \%$ to $39 \%) ; 20$ patients $(40 \%)$ achieved stable disease. Median PFS was 4.4 (95\% CI=2.8-8.3) months and median OS was 18.0 (95\% CI=16.2-30.7) months (Figure 1A and B, respectively). PFS was significantly higher among responders (CR and partial response) compared to non-responders (stable disease) (Figure 2A). However, OS was not significantly correlated with the type of response (Figure 2B).

Survival outcomes according to molecular profile. EGFR mutation-positive status but not expression significantly improved PFS $(p<0.001)$ but not OS $(p=0.0913)$ Patients who were pretreated with a reversible tyrosine kinase inhibitor (TKI) as standard first-line treatment achieved a PFS of 13.8 months (95\% CI=8.7-27.5). In contrast, lower median expression of TIMP was significantly associated with better OS, but not PFS (Figure 3A and B).

Toxicity. The most common severe toxicity (>grade 3 ) was hematological toxicity: $32 \%$ of patients encountered neutropenia and $8.3 \%$ thrombocytopenia. The most frequent non-hematopoietic toxicity was diarrhea and arterial hypertension in about $5 \%$ of patients.

\section{Discussion}

This study documented favorable clinical survival endpoints in a cohort of patients with advanced NSCLC treated with irinotecan and bevazizumab. A higher OS was reached 

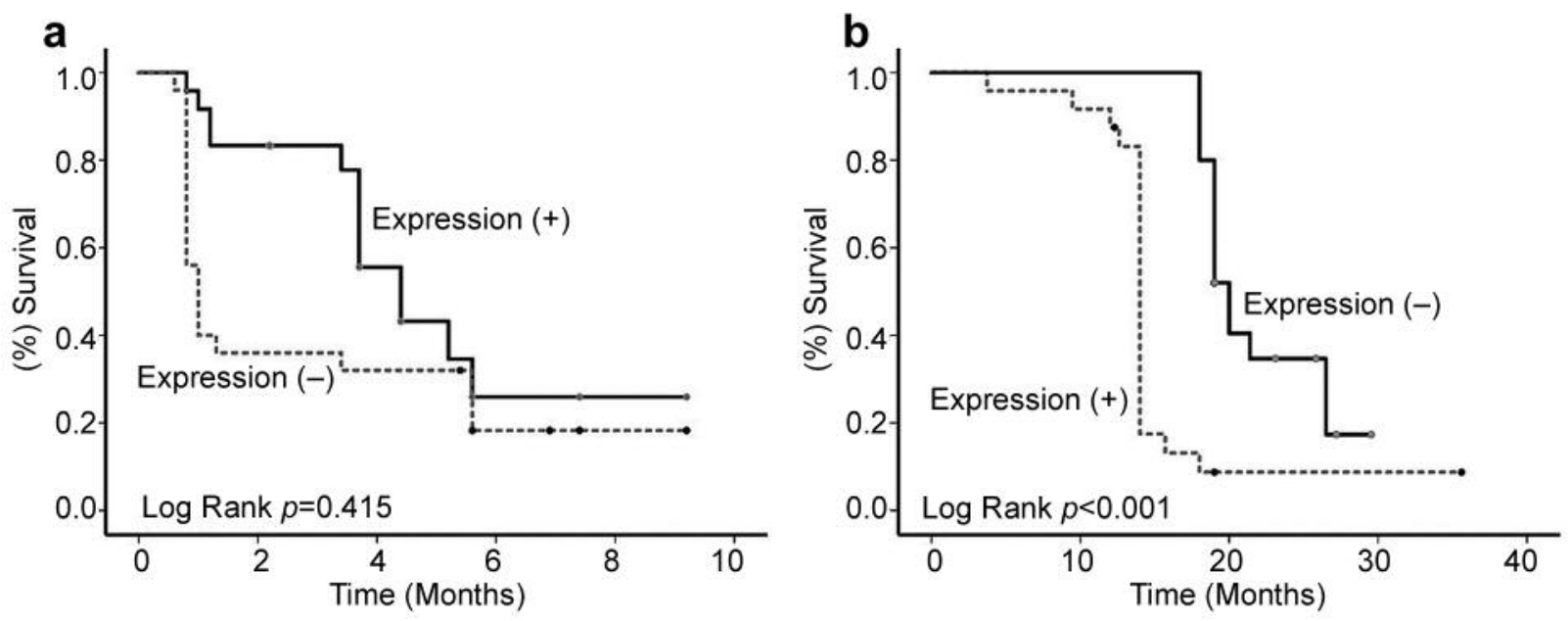

Figure 3. Progression-free $(A)$ and overall $(B)$ survival among patients treated with irinotecan plus bevacizumab based on tissue inhibitor of metalloproteinases-1 expression.

compared to that reported for most large phase III trials, which have shown a median survival of 8 to 10 months (36). Likewise, a PFS similar to NJLCG0703 (30), was encountered. A favorable treatment response higher than in other studies of Irinotecan in metastatic NSCLC, such as an ORR of $18.8 \% \quad(95 \% \quad \mathrm{CI}=5.3-32.3)$ documented by Matsubara et al. (30) was also observed. The better outcomes of this study are possibly explained by the combination therapy with bevacizumab.

Furthermore, the impact of TIMPI and EGFR mutation status on clinical outcomes was studied. EGFR mutation status was associated with significantly longer PFS, OS and longer lasting response; consistent with several trials that have shown that EGFR mutations are important predictors of treatment response to TKIs in patients with NSCLC (27-29). However, some patients with mutations do not achieve a favorable outcome, suggesting that factors other than EGFR-TKI exposure contribute to the longer survival. In an effort to increase treatment efficacy and manage resistance to EGFR, researchers have postulated VEGF therapy in NSCLC harboring EGFR mutations in order to enhance antitumor activity, especially in cells that express high levels of VEGF (37). The JO25567 study was a randomized phase II study that evaluated the efficacy of combination therapy with erlotinib and bevacizumab versus erlotinib alone in patients with stage III/IV NSCLC harboring EGFR-activating mutation (38). This trial showed that the PFS of the combination therapy group was longer than that of the erlotinib monotherapy group. The present study supports this finding, as documented by a notable efficacy with combination chemotherapy. However, the PFS was lower compared to JO25567, which documented a median PFS of 16.0 (95\% CI=13.9-18.1) months with erlotinib plus bevacizumab, a finding possibly explained by duration of exposure to the antiangiogenic.
Although EGFR overexpression has been shown to correlate with poor prognosis (39), OS was not affected by its expression. Additionally, these results support the hypothesis that higher TIMP1 expression is associated with a poor prognosis. This is consistent with Pesta et al. who reported a shorter disease-free interval in patients with a higher expression of TIMP1 mRNA in tumor tissue. A relationship between tumor tissue TIMP1 mRNA expression and disease-free interval in squamous cell carcinoma $(p=0.0117)$ was also documented. Shorter OS was found in patients at advanced stages with a higher expression of TIMP1 mRNA ( $p=0.0389)(35,40)$. Regarding safety, it has been suggested that irinitocan/bevacizumab is well tolerated as third-line or higher therapy for NSCLC. Frequencies of major hematological toxicities were comparable to other trials $(7,30)$. Moreover, no treatment-related deaths occurred.

\section{Conclusion}

The present study demonstrates reasonable efficacy and acceptable toxicity of irinotecan plus bevacizumab as a thirdor fourth-line treatment for NSCLC in Hispanic patients. Results suggest that this is a considerable option, particularly for those harboring EGFR mutations and low TIMP1 expression. However, this was a small-scale study with a single-arm design, thus, these conclusions need to be confirmed in large-scale prospective studies.

Patients harboring EGFR mutations tend to have better prognosis compared to patients without mutated receptors. New molecular markers have been recently studied and correlated with clinical endpoints in patients with advanced NSCLC. Agents such as bevacizumab and irinotecan offer gain in survival endpoints in certain patients; however, they are reserved as a third or fourth line of treatment. The 
inclusion of this novel therapeutic strategy as a third-orfourth line treatment could offer patients a greater survival benefit. Measurement of TIMP1 expression as a standard of practice could offer a decision-making tool for medical oncologists in selecting patients for more aggressive treatments of additional chemotherapeutic agents.

\section{Disclaimer}

Preliminary results from this study were previously shared during the 2014 LALCA Meeting (August 21-23, 2014 Lima, Peru) and the 16th World Conference on Lung Cancer (September 4-9, 2015 Denver, Colorado, USA - Abstract 2521).

\section{Funding}

This work was supported by the Foundation for Clinical and Applied Cancer Research- FICMAC (Bogotá, Colombia) research grant 020-2014.

\section{Conflict of Interest}

The Authors declare they have no competing conflict of interest to declare.

\section{References}

1 Giroux Leprieur E, Lavole A, Ruppert AM, Gounant V, Wislez M, Cadranel J and Milleron B: Factors associated with long-term survival of patients with advanced non-small cell lung cancer. Respirology 17: 134-142, 2012.

2 Ozkaya S, Findik S, Dirican A and Atici AG: Long-term survival rates of patients with stage IIIB and IV non-small cell lung cancer treated with cisplatin plus vinorelbine or gemcitabine. Exp Ther Med 4: 1035-1038, 2012.

3 Ahbeddou N, Fetohi M, Boutayeb S and Errihani H: Which nonsmall-cell lung cancer patients achieve long-term survival? Indian J Cancer 48: 514-515, 2011.

4 Sanchez L, Lorenzo-Luaces P, Viada C, Galan Y, Ballesteros J, Crombet $\mathrm{T}$ and Lage $\mathrm{A}$ : Is there a subgroup of long-term evolution among patients with advanced lung cancer?: hints from the analysis of survival curves from cancer registry data. BMC Cancer 14: 933, 2014.

5 Hsiang YH, Hertzberg R, Hecht S and Liu LF: Camptothecin induces protein-linked DNA breaks via mammalian DNA topoisomerase I. J Biol Chem 260: 14873-14878, 1985.

6 Hsiang YH and Liu LF: Identification of mammalian DNA topoisomerase I as an intracellular target of the anticancer drug camptothecin. Cancer Res 48: 1722-1726, 1988.

7 Ohe Y, Ohashi Y, Kubota K, Tamura T, Nakagawa K, Negoro S, Nishiwaki Y, Saijo N, Ariyoshi Y and Fukuoka M: Randomized phase III study of cisplatin plus irinotecan versus carboplatin plus paclitaxel, cisplatin plus gemcitabine, and cisplatin plus vinorelbine for advanced non-small-cell lung cancer: Four-Arm Cooperative Study in Japan. Ann Oncol 18: 317-323, 2007.

8 Magrini R, Bhonde MR, Hanski ML, Notter M, Scherübl H, Boland CR, Zeitz M and Hanski C: Cellular effects of CPT-11 on colon carcinoma cells: dependence on p53 and hMLH1 status. Int J Cancer 101: 23-31, 2002.
9 Hurwitz HI, Tebbutt NC, Kabbinavar F, Giantonio BJ, Guan ZZ, Mitchell L, Waterkamp D and Tabernero J: Efficacy and safety of bevacizumab in metastatic colorectal cancer: pooled analysis from seven randomized controlled trials. The oncologist 18 : 1004-1012, 2013.

10 Cao R, Zhang S, Ma D and Hu L: A multi-center randomized phase II clinical study of bevacizumab plus irinotecan, 5fluorouracil, and leucovorin (FOLFIRI) compared with FOLFIRI alone as second-line treatment for Chinese patients with metastatic colorectal cancer. Medical oncology 32: 325, 2015.

11 Sakai A, Kasahara K, Ohmori T, Kimura H, Sone T, Fujimura M and Nakao S: MET increases the sensitivity of gefitinib-resistant cells to SN-38, an active metabolite of irinotecan, by up-regulating the topoisomerase I activity. J Thorac Oncol 7: 1337-1344, 2012.

12 Brew K, Dinakarpandian D and Nagase H: Tissue inhibitors of metalloproteinases: evolution, structure and function. Biochim Biophys Acta 1477: 267-283, 2000.

13 Hayakawa T, Yamashita K, Tanzawa K, Uchijima E and Iwata $\mathrm{K}$ : Growth-promoting activity of tissue inhibitor of metalloproteinases-1 (TIMP-1) for a wide range of cells. A possible new growth factor in serum. FEBS Lett 298: 29-32, 1992.

14 Corcoran ML and Stetler-Stevenson WG: Tissue inhibitor of metalloproteinase-2 stimulates fibroblast proliferation via a cAMPdependent mechanism. J Biol Chem 270: 13453-13459, 1995.

15 Yamashita K, Suzuki M, Iwata H, Koike T, Hamaguchi M, Shinagawa A, Noguchi $\mathrm{T}$ and Hayakawa $\mathrm{T}$ : Tyrosine phosphorylation is crucial for growth signaling by tissue inhibitors of metalloproteinases (TIMP-1 and TIMP-2). FEBS Lett 396: 103-107, 1996.

16 Bunatova K, Pesta M, Kulda V, Topolcan O, Vrzalova J, Sutnar A, Treska V, Pecen L and Liska V: Plasma TIMP1 level is a prognostic factor in patients with liver metastases. Anticancer Res 32: 4601-4606, 2012.

17 Hekmat O, Munk S, Fogh L, Yadav R, Francavilla C, Horn H, Würtz S, Schrohl AS, Damsgaard B, Rømer MU, Belling KC, Jensen NF, Gromova I, Bekker-Jensen DB, Moreira JM, Jensen LJ, Gupta R, Lademann U, Brünner N, Olsen JV and Stenvang $\mathrm{J}$ : TIMP-1 increases expression and phosphorylation of proteins associated with drug resistance in breast cancer cells. J Proteome Res 12: 4136-4151, 2013.

18 Birgisson H, Nielsen HJ, Christensen IJ, Glimelius B and Brünner N: Preoperative plasma TIMP-1 is an independent prognostic indicator in patients with primary colorectal cancer: a prospective validation study. Eur J Cancer 46: 3323-3331, 2010.

19 Jensen SA, Vainer B, Bartels A, Brünner N and Sørensen JB: Expression of matrix metalloproteinase 9 (MMP-9) and tissue inhibitor of metalloproteinases 1 (TIMP-1) by colorectal cancer cells and adjacent stroma cells--associations with histopathology and patients outcome. Eur J Cancer 46: 3233-3242, 2010.

20 Talvensaari-Mattila A and Turpeenniemi-Hujanen T: High preoperative serum TIMP-1 is a prognostic indicator for survival in breast carcinoma. Breast Cancer Res Treat 89: 29-34, 2005.

21 Würtz S, Møller S, Mouridsen H, Hertel PB, Friis E and Brünner $\mathrm{N}$ : Plasma and serum levels of tissue inhibitor of metalloproteinases-1 are associated with prognosis in node-negative breast cancer: a prospective study. Mol Cell Proteomics 7: 424-430, 2008.

22 Honkavuori M, Talvensaari-Mattila A, Puistola U, TurpeenniemiHujanen T and Santala M: High serum TIMP-1 is associated with adverse prognosis in endometrial carcinoma. Anticancer Res 28: 2715-2719, 2008. 
23 Spindler KL, Christensen IJ, Nielsen HJ, Jakobsen A and Brünner N: TIMP-1 and CEA as biomarkers in third-line treatment with irinotecan and cetuximab for metastatic colorectal cancer. Tumour Biol 36: 4301-4308, 2015.

24 Negoro S, Masuda N, Takada Y, Sugiura T, Kudoh S, Katakami $\mathrm{N}$, Ariyoshi Y, Ohashi Y, Niitani H, Fukuoka M and West CLCSG: Randomised phase III trial of irinotecan combined with cisplatin for advanced non-small-cell lung cancer. Br J Cancer 88: 335-341, 2003.

25 Schiller JH, Harrington D, Belani CP, Langer C, Sandler A, Krook J, Zhu J, Johnson DH and Group ECO: Comparison of four chemotherapy regimens for advanced non-small-cell lung cancer. N Engl J Med 346: 92-98, 2002.

26 Reck M, von Pawel J, Zatloukal P, Ramlau R, Gorbounova V, Hirsh V, Leighl N, Mezger J, Archer V, Moore N and Manegold C: Phase III trial of cisplatin plus gemcitabine with either placebo or bevacizumab as first-line therapy for nonsquamous non-small-cell lung cancer: AVAil. J Clin Oncol 27: 1227-1234, 2009.

27 Shepherd FA, Rodrigues Pereira J, Ciuleanu T, Tan EH, Hirsh V, Thongprasert S, Campos D, Maoleekoonpiroj S, Smylie M, Martins R, van Kooten M, Dediu M, Findlay B, Tu D, Johnston D, Bezjak A, Clark G, Santabárbara P, Seymour L and Group NCIoCCT: Erlotinib in previously treated non-small-cell lung cancer. N Engl J Med 353: 123-132, 2005.

28 Zhang WQ, Li T,and Li H: Efficacy of EGFR tyrosine kinase inhibitors in non-small-cell lung cancer patients with/without EGFR-mutation: evidence based on recent phase III randomized trials. Med Sci Monit 20: 2666-2676, 2014.

29 Lynch TJ, Bell DW, Sordella R, Gurubhagavatula S, Okimoto RA, Brannigan BW, Harris PL, Haserlat SM, Supko JG, Haluska FG, Louis DN, Christiani DC, Settleman J and Haber DA: Activating mutations in the epidermal growth factor receptor underlying responsiveness of non-small-cell lung cancer to gefitinib. N Eng1 J Med 350: 2129-2139, 2004.

30 Matsubara N, Maemondo M, Inoue A, Ishimoto O, Watanabe K, Sakakibara T, Fukuhara T, Morikawa N, Tanaka M, Sugawara S and Nukiwa T: Phase II study of irinotecan as a third- or fourthline treatment for advanced non-small cell lung cancer: NJLCG0703. Respir Investig 51: 28-34, 2013.

31 Eisenhauer EA, Therasse P, Bogaerts J, Schwartz LH, Sargent D, Ford R, Dancey J, Arbuck S, Gwyther S, Mooney M, Rubinstein L, Shankar L, Dodd L, Kaplan R, Lacombe D and Verweij J: New response evaluation criteria in solid tumours: revised RECIST guideline (version 1.1). Eur J Cancer 45: 228$247,2009$.

32 Services UDoHaH: Common terminology criteria for adverse events (CTCAE) version 4.0. National Cancer Institute 2009.

33 Travis WD, Brambilla E, Noguchi M, Nicholson AG, Geisinger KR, Yatabe Y, Beer DG, Powell CA, Riely GJ, Van Schil PE,
Garg K, Austin JH, Asamura H, Rusch VW, Hirsch FR, Scagliotti G, Mitsudomi T, Huber RM, Ishikawa Y, Jett J, SanchezCespedes M, Sculier JP, Takahashi T, Tsuboi M, Vansteenkiste J, Wistuba I, Yang PC, Aberle D, Brambilla C, Flieder D, Franklin W, Gazdar A, Gould M, Hasleton P, Henderson D, Johnson B, Johnson D, Kerr K, Kuriyama K, Lee JS, Miller VA, Petersen I, Roggli V, Rosell R, Saijo N, Thunnissen E, Tsao M and Yankelewitz D: International association for the study of lung cancer/american thoracic society/european respiratory society international multidisciplinary classification of lung adenocarcinoma. J Thorac Oncol 6: 244-285, 2011.

34 Hirsch FR, Dziadziuszko R, Thatcher N, Mann H, Watkins C, Parums DV, Speake G, Holloway B, Bunn PA and Franklin WA: Epidermal growth factor receptor immunohistochemistry: comparison of antibodies and cutoff points to predict benefit from gefitinib in a phase 3 placebo-controlled study in advanced nonsmall-cell lung cancer. Cancer 112: 1114-1121, 2008.

35 Pesta M, Holubec L, Topolcan O, Cerna M, Rupert K, Holubec LS, Treska V, Kormunda S, Elgrova L, Finek J and Cerny R: Quantitative estimation of matrix metalloproteinases 2 and 7 (MMP-2, MMP-7) and tissue inhibitors of matrix metalloproteinases 1 and 2 (TIMP-1, TIMP-2) in colorectal carcinoma tissue samples. Anticancer Res 25: 3387-3391, 2005.

36 Socinski MA, Morris DE, Masters GA, Lilenbaum R and Physicians ACoC: Chemotherapeutic management of stage IV non-small cell lung cancer. Chest 123: 226S-243S, 2003.

37 Wheeler DL, Dunn EF and Harari PM: Understanding resistance to EGFR inhibitors-impact on future treatment strategies. Nat Rev Clin Oncol 7: 493-507, 2010.

38 Seto $\mathrm{T}$, Kato $\mathrm{T}$, Nishio $\mathrm{M}$, Goto $\mathrm{K}$, Atagi S, Hosomi $\mathrm{Y}$, Yamamoto N, Hida T, Maemondo M, Nakagawa K, Nagase S, Okamoto I, Yamanaka T, Tajima K, Harada R and Fukuoka M: Erlotinib alone or with bevacizumab as first-line therapy in patients with advanced non-squamous non-small-cell lung cancer harbouring EGFR mutations (JO25567): an open-label, randomised, multicentre, phase 2 study. Lancet Oncol 15: 12361244,2014

39 Sharma SV, Bell DW, Settleman J and Haber DA: Epidermal growth factor receptor mutations in lung cancer. Nat Rev Cancer 7: 169-181, 2007.

40 Rojiani MV, Ghoshal-Gupta S, Kutiyanawalla A, Mathur S and Rojiani AM: TIMP-1 overexpression in lung carcinoma enhances tumor kinetics and angiogenesis in brain metastasis. $\mathrm{J}$ Neuropathol Exp Neurol 74: 293-304, 2015.

Received June 14, 2017

Revised July 13, 2017

Accepted July 17, 2017 